\title{
El arte local en el contexto global
}

\section{lida, Cecilia}

Resumen:

En los últimos tiempos el interés de los grandes centros sobre las periferias deviene de los procesos de descolonización, globalización y demográficos. En el nuevo orden mundial, el circuito artístico ha sufrido modificaciones, que conducen a repensarlo como un campo de intereses y negociaciones. La perspectiva pluralista del mundo posmoderno ha impulsado la inclusión de las periferias dentro de las exhibiciones internacionales de arte. Al considerar a los curadores de las exposiciones de arte internacional como agentes sociales de control del sentido del arte, es posible repensar su rol como un aspecto esencial en la inclusión de las periferias dentro de aquel campo artístico. Desde esta

Cuadernos del Centro de Estudios de Diseño y Comunicación Nº 60

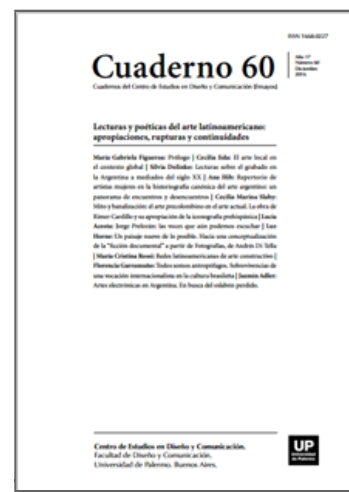

ISSN: 1668-0227

Lecturas y poéticas

del arte

latinoamericano:

apropiaciones,

rupturas y

continuidades

Argentina | 176 páginas

Año XVII, Diciembre 2016, Buenos Aires,

descargar PDF

ver índice de la publicación

Ver todos los libros de la publicación

compartir en Facebook

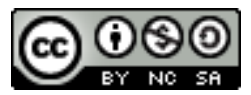

Esta obra está bajo una Licencia Creative Commons Atribución-NoComercialCompartirlgual 4.0 Internacional

perspectiva, se reflexionará sobre,

hasta qué punto las prácticas curatoriales, no son también estrategias políticas y sociales; construcciones discursivas que modelan no solo una concepción del espacio artístico sino que, a través de la misma, impulsan una lectura del mundo.

Palabras clave:

arte latinoamericano - prácticas curatoriales - local - global - pluralismo posmoderno - campo artístico occidentalización - internacionalismo.

"Hacer arte supone una revelación, porque implica sacar a relucir la verdad, que yace en lo más profundo del país, para llevarla a la escena, al papel o al cuadro. Pero hacer eso entre nosotros, significa crearlo todo de nuevo". (Rodolfo Kusch, "Traición o Cultura", 1960) El vínculo entre arte e identidad, que para Kusch es inevitable y profundo, es un tema que nos atraviesa e insiste, desde diferentes épocas y con matices diversos. Desde los procesos independentistas hasta hoy, cada nuevo reposicionamiento histórico supuso, y supone, una reflexión que se debate entre lo propio y lo ajeno y una permanente reinvención de sí. 
En todo pensamiento o teoría que se pregunta por un arte propio, emerge la cuestión del impacto de occidente en el contexto local. Es entonces que los vínculos entre Latinoamérica y los centros hegemónicos deviene un asunto central: los sucesivos impactos del proceso de occidentalización1 permiten pensar no solo en la relación con los centros hegemónicos europeos sino también -tras la posguerra- con Norteamérica y en las últimas décadas, los mismos focos de poder se configuran bajo nuevas formas dominantes tras la idea de un campo artístico internacional. En los últimos años, el impulso de las economías globales implicó un reposicionamiento de las naciones así como un nuevo lugar para las producciones artísticas latinoamericanas.

La definición de cuál es ese lugar y quienes asumen o portan el poder para definirlo es un aspecto esencial. En el campo local y en el circuito artístico internacional, se debaten intereses y negociaciones de sentido que hacen a un posicionamiento geopolítico. La reflexión sobre la identidad latinoamericana es tema de análisis dentro y fuera de la región.

La perspectiva pluralista del mundo posmoderno ha otorgado un nuevo impulso a la inclusión del arte local en las exhibiciones internacionales. Desde este marco, considerando a los curadores de las exposiciones de arte internacional como agentes sociales de control del sentido del arte, es posible repensar su rol como un aspecto esencial en la inclusión de las periferias dentro de aquel campo artístico. Desde esta perspectiva, es posible pensar las prácticas curatoriales como construcciones discursivas que modelan no solo una concepción del espacio artístico sino que, a través de la misma, impulsan también una lectura del mundo. La inclusión del arte Latinoamericano en el campo artístico internacional

En el marco de la Guerra Fría, el mundo es organizado a partir de los bloques hegemónicos opuestos liderados por Estados Unidos y la Unión de Repúblicas Socialistas Soviéticas.

En este contexto, Estados Unidos buscando el reconocimiento europeo organiza una campaña propagandística que, según Eva Cocroft2, alía las políticas internacionales y las instituciones artísticas. La proyección de Estados Unidos como una Nación que promueve la "expresión libre" y la idea de "sociedad abierta y libre" en contraposición del Bloque soviético, implicó una red institucional entre la Oficina de Asuntos Interamericanos (dirigida por Nelson Rockefeller desde 1940), y el MOMA (fundado en 1929, principalmente por los esfuerzos de John D. Rockefeller). Estos vínculos promovieron la exportación de exhibiciones de arte norteamericanas principalmente del Expresionismo Abstracto3- hacia diversas partes del mundo. En los años cincuenta la mirada norteamericana se dirige principalmente a Europa donde se busca la legitimación que colaborará en la instauración de Estados Unidos como potencia mundial. En este contexto, frente a las políticas bilaterales, emerge el Tercer Mundo. Este tercer espacio simbólico y geográfico, compuesto por África, Asia y Latinoamérica, permanece marginal siendo solo alternativamente receptor de dichas producciones artísticas4. Sólo una década después y durante un breve periodo se verán con mayor asiduidad producciones artísticas latinoamericanas en Estados Unidos.

A causa de la emergencia de la Revolución Cubana y con el interés de refrenar la expansión del comunismo en el resto de los países latinos, se realizarán conferencias y exposiciones de arte latinoamericano en las oficinas del Centro para las Relaciones Interamericanas.

En la década del sesenta, el proceso de descolonización en África y Asia será uno de los aspectos importantes para la consolidación de las identidades políticas minoritarias emergentes en el Primer Mundo. Para Fredric 
Jameson5, las luchas de liberación nacional promueven modelos políticos y culturales que impulsan en Europa y en Estados Unidos la emergencia de nuevos sujetos de la historia: movimientos negros y feministas instalan la lucha por la diferencia y la identidad, oponiéndose al sistema tal como estaba instituido. Sin embargo, desde la perspectiva de Jameson6, el proceso de descolonización irá de la mano del neocolonialismo. Para el autor se trata de una época en la que el capital se encuentra en una nueva expansión dinámica e innovadora que implica la propagación y penetración del capitalismo en el Tercer Mundo. Los ‘60 como punto de quiebre y transición a un nuevo mundo global, plantea la permanencia de las relaciones dialécticas de resistencia y dominación.

Con el antecedente de la articulación de las minorías en centros y periferias, podría pensarse la posterior inclusión de los latinos como nuevos sujetos subalternos. La larga historia de migraciones masivas y exilios de sud y centroamericanos a los Estados Unidos los convierte hoy en una de las minorías más grandes en éste país. El proceso de su asimilación ha generado modificaciones en la cultura política y jurídica, en los hábitos de consumo y estrategias educativas, artísticas y comunicacionales en varios estados7. La necesidad de encontrar estrategias de control de las diferencias también se evidencian en el campo artístico. Un caso ejemplar de la época que evidencia las tensiones y contradicciones de dicho proceso es la exposición Artistas Latinoamericanos del siglo XX (1993). Muestra itinerante que visita París, Colonia, Venecia y Nueva York. Su curador, Waldo Rasmussen8, se proponía incorporar la producción artística latinoamericana de todo el siglo al escenario artístico internacional. En ese sentido argumentó: "América Latina está aquí en Nueva York, así como en todos los Estados Unidos. Por esta razón es de gran importancia [...] incluir a los artistas latinos en esta exposición y darles un lugar dentro del contexto internacional” 9.

El interés se centró en presentar subjetividades individuales y no identidades culturales específicas, por lo cual la propuesta curatorial fue concebida a partir de una lectura lineal de la historia del arte y en base a rasgos estilísticos. Se planteó que el arte debe ser exhibido en términos internacionales y no nacionales, ya que no se consideraba que se haga un servicio al arte exponiéndolo en términos de mostrar a Argentina y luego Brasil y México. Creo que eso nada tiene que ver con el arte10.

Waldo Rasmussen fue director del Programa Internacional del MOMA desde los ‘50, donde se desempeñó como exportador oficial de exposiciones11. En la muestra, el borramiento de lo local enfatizando un supuesto lenguaje artístico internacional, aun cuando se adjetiven las diferencias, sostiene y reitera en los noventa, el modelo de "arte autónomo" presente en las políticas culturales internacionales norteamericanas y en las constelaciones teóricas de Clement Greenberg o Alfred Barr en el período de la Guerra Fría. Así, el interés de los centros hegemónicos sobre el arte latinoamericano deviene de los procesos de descolonización, globalización y demográficos. El agotamiento de las políticas imperialistas es sustituido por nuevas formas de control, como el capitalismo global donde la paradoja reside en la colonización sin la metrópolis colonizante de tipo Estado Nación12. Entre lo universal y lo particular: Latinoamérica en los modelos curatoriales

internacionales

La inevitable incorporación del otro dentro y fuera de las fronteras marcó la necesidad de nuevas teorías13 para nuevos problemas, y su inscripción en la escena artística y cultural implicó la emergencia de nuevos programas artísticos, exposiciones y eventos culturales14 que plantearan la articulación de las diferencias 15. Como contrapartida, las exhibiciones de arte internacional han intentado promover como espacio de encuentros interculturales organizando dichos territorios según categorías diversas: representaciones nacionales como en 
Venecia y San Pablo; representaciones por región como Mercosur, Cuenca; o representaciones sobre disciplinas o sobre problemáticas específicas16. En estas exposiciones los modelos curatoriales justifican y valoran un modo de articulación del mundo, una forma de pensarlo que hace del circuito artístico internacional un espacio de disputa por la legitimidad, así como también de emergencia de alternativas de sentido y prácticas diversas. Siguiendo estas ideas podrían distinguirse entre las curadurías que en la tensión entre lo local y lo global intentan proponer zonas de encuentros interculturales más allá de las diferencias -haciendo así de la exposición un espacio transnacional de exhibición-; y otras propuestas curatoriales que más allá del eje inclusión-exclusión buscan problematizar las diferencias.

En relación al primer modelo mencionado cabe pensar el análisis que la investigadora Valeria González17 establece sobre la propuesta curatorial de Harald Szeemann en la 49ª Bienal de Venecia del 2001, donde el curador propone el núcleo internacional titulado "Platea de la Humanidad". En esta edición, Szeemann pensó un escenario universal de representación igualitaria en el que convivían las más diversas culturas visuales. Un escenario en el que la idea de globalización -entendida como la circulación entre centros que ya no se definen necesariamente por las naciones-, permitía repensar las exhibiciones internacionales como espacios transnacionales. Espacios que disuelven las fronteras que antes separaban los estados nacionales, y consecuentemente, la tendencia hacia la universalización y homogenización. Cabe aclarar que aún cuando la organización del evento esté prefijada por la modalidad de "representaciones nacionales", lo transnacional se presenta como modelo discursivo por sobre la organización territorial; el sistema valorativo partiría de los rasgos legitimantes propuestos por los centros hegemónicos del mainstream. De esta manera, lo global ha impulsado la legitimación de una mirada universalizante que se fortalece en la tendencia de atomización en núcleos diversificados pero donde se mantiene el privilegio de una mirada dominante18.

Desde otra perspectiva pero también en relación al primer modelo adquiere sentido la línea curatorial que Alfons Hug propuso para la $26^{a}$ Bienal de San Pablo en el 2004. La lectura de su escrito "La Bienal como Territorio Libre"19, permite considerar como eje del discurso del curador la reafirmación del carácter internacional de la Bienal de San Pablo.

Según Hug, como consecuencia del carácter multicultural de Brasil, la Bienal de San Pablo "foi tambén un corretivo do eurocentrismo de Kassel y Venecia. Estava até predestinada a cumplir esse papel"20. El papel es cumplido por San Pablo al abrirse al mundo, por lo cual, según el curador, la bienal fundada en 1951 se inicia representando más de veinte países, y en los sesenta representa a cincuenta naciones; en detrimento considera que la Bienal de Venecia, "començou em 1895 com um punhado de paises europeus"21. Más adelante, refiriéndose a la bienal brasileira, agrega: "foi verdaderamente internacional desde o início e dirigiu o seu olhar para o mundo"22. Dos observaciones se deslizan de estas ideas: por un lado, el curador convierte la internacionalidad en una cualidad de status, de legitimación de las bienales -lo cual, paradójicamente, funciona también como correctivo del eurocentrismo-; y por otro lado, lo internacional -entendido aquí como sinónimo de inclusión- devendría más bien en una cuestión cuantitativa que cualitativa. Es posible pensar que este discurso curatorial, más allá de problematizar la articulación de las periferias, se contenta con la inclusión abultada de las mismas. De alguna forma, tras la idea de ser la primer bienal que establece un diálogo entre naciones, lo que oculta es que dicho carácter inclusivo otorga legitimidad como un espacio internacional por excelencia. En última instancia, es la inclusión de diversos países lo que hace de San Pablo una Bienal "verdadeiramente internacional" para el curador23. Otro aspecto a señalar es la organización espacial, donde las Representaciones Nacionales y los Artistas Invitados conviven en un mismo espacio, que como plantea él 
mismo plantea "a pesar de toda complexidade das diverzas vozes, cria-se desse modo um concerto colectivo"24. Así desde la organización espacial, más que un modelo internacional se constituye un espacio transnacional -de alguna forma, un no lugar- de inscripción que homogeniza lo diverso. Finalmente, el eje temático es la idea de territorio libre, donde el arte como campo autónomo instituye un espacio simbólico, metafórico y más feliz25, en el cual más allá de las diferencias de la realidad misma "no dominio da estética, nada é de ninguém; e tudo é de todos"25. Según esta concepción, es posible proponer que en este caso el marco de legitimación para incluir las periferias está sobredeterminado por un punto de vista homogenizador que reproduce conceptualmente los modelos tradicionales de legitimación.

En contraste, cabe distinguir otra línea de reflexión como el modelo curatorial planteado por la $24^{a}$ Bienal de San Pablo (1998) en la que Paulo Herkenhoff partió del eje de la antropofagia26 como marco para pensar desde una perspectiva encarnada en y desde Brasil la historia del arte local e internacional. Otro quiebre en este sentido lo representa la propuesta de Lisette Lagnado, curadora en la 27ª Bienal de San Pablo del 2006; en la cual, abandonando la organización basada en las representaciones nacionales se configuró un campo de similitudes, contrastes, vínculos y tensiones que reflexionaba sobre la convivencia en la diversidad. Como vivir juntos fue el título elegido por Lagnado para aquella edición. El interrogante es el tema central del seminario dictado por Roland Barthes entre 1976 y 1977 en el Collège de France. El filósofo propone allí la noción de idiorritmia como deseo y utopía del vivir juntos-solos, y lo ejemplifica con modos de convivencias en el que se integra el propio ritmo27. Pensar la bienal como un espacio “idiorritmico, como una puesta en común de las distancias"28, le permitía a la curadora poner en diálogo un conjunto de emprendimientos sociales específicos, que aun conservando su propio ritmo, podían ser vinculados, contrastados o puestos en tensión. En ese sentido, podían emerger las diferentes lecturas entre las propuestas.

Es evidente que los espacios de exhibición del mainstream definen parámetros estrechos para el arte periférico es una evidencia. Aún así, el contraste entre los modelos curatoriales permite establecer diferencias que modifican la lectura de las propuestas que allí se presentan. Es decir que los marcos conceptuales curatoriales rigen cierta lectura de las producciones estéticas expuestas.

Finalmente, cabe referir a la preferencia de las muestras internacionales de incluir a artistas latinoamericanos cuyas obras problematicen cuestiones o temas específicamente locales. En ese sentido, para Gerardo Mosquera "el arte de otras culturas debe ser original pero construir su otredad en un sentido en el que pueda ser aceptado por un centro"29. Mientras que para Joaquín Barriendos: La visión romántica y neoprimitivista sobre el arte de las periferias se materializa por medio del prejuicio de que fuera de occidente los artistas están más en contacto con la realidad, con el 'pueblo' y con las multitudes y que, por lo tanto, son más 'originales' o 'puros' y su arte más verídico, más 'real', más efectivo (políticamente hablando). Esta sublimación de lo subalterno o romantización de lo marginal genera una poética de lo reivindicativo que objetualiza la alteridad, codificándola y haciéndola fácilmente consumible y absorbible30. Desde estas perspectivas pareciera que las prácticas artísticas locales en el campo global se encuentran en la encrucijada de inscribirse en un circuito que legitima la universalidad del arte pero que, al mismo tiempo, exige dar cuenta de los contextos locales; y sin embargo, cabe recordar también colectivos de artistas y propuestas que, con breves participaciones en el mundo internacional, han buscado desbordarlo y excederlo. Grupos como las activistas bolivianas Mujeres Creando, que utilizan la creatividad como instrumento de combate y construcción. Activistas que literalmente exceden los marcos del arte para trabajar en y con la sociedad que las rodea. Otras propuestas, quizás respuestas específicamente coyunturales, como el ya desaparecido Taller Popular de Serigrafía (TPS) de la Argentina que elaboró 
estrategias para incidir y participar creativa y activamente en las luchas sociales en el contexto de la crisis del 2001. Sobre quienes cabe referir que ambos grupos participaron de la bienal curada por Lagnado. Allí las propuestas de estos colectivos contrastaba por la perspectiva en la que ambos entendieron su participación en un espacio internacional. Por su parte, Mujeres Creando, -quienes no se piensan a sí mismas como artistas sino como mujeres que utilizan la creación como herramienta de lucha-, exhibían una intervención artística con fotografías y grafitis que apostaba a la reflexión social de la historia boliviana en el contexto de la bienal; y por otra parte el Taller Popular de Serigrafía presentaba un archivo compuesto por el repertorio iconográfico serigrafiado y banderas estampadas instalando un dispositivo crítico que ponía en evidencia la dificultad para asir la experiencia estético política en el contexto artístico internacional. Así, en el contraste, las propuestas más que ser concebidas como parte de una plataforma de semejanzas diversas, permitían repensar y problematizar las tensiones entre lo local y lo global.

Es evidente que el termómetro internacional mide el arte local según su contemporaneidad y las relaciones que establecen con una realidad que suponen previamente conflictiva.

Y aún así, que los artistas desdibujen barreras entre el arte y la política, que participen activamente en situaciones de la realidad diaria sigue siendo fundamental. Por esto, aun cuando sean trasladados al campo artístico internacional, creo que es fundamental evitar el reduccionismo que reproduce y sostiene un sistema de jerarquías económicas y sociopolíticas que ignora que los rasgos estéticos y políticos del arte activista latinoamericano son elecciones, herramientas y estrategias que evidencian una voluntad activa para el cambio y la transformación de la realidad que nos rodea. En ese sentido, es preciso apostar a lecturas que mas que homogeneizar las diferencias apueste a repensarlas y problematizarlas. Notas

1. Se plantea la noción de occidentalización en el sentido que le otorga Walter Mignolo a través del pensamiento de Fernández Retamar. Según el primero, "Para los pensadores en América Latina, el cruce y superposición de poderes imperiales se concibió no tanto en términos de colonización sino de occidentalización", Mignolo, Walter, "Pos-occidentalismo el argumento de América Latina", http://www.perio.unlp.edu.ar/catedras/system/files/ mignolo._postoccidentalismo.pdf 2. Cockroft, E. (1974). "Abstract Expresionism, Weapon of the Cold War", Artforum. June, 1974.

3. Según Eva Cocroft, el movimiento artístico respondía idealmente a las actividades de propaganda por su carácter "vanguardista y original", que mostraba a su país al mismo nivel que París. Ibid.

4. La oficina de Asuntos Interamericanos, hacia fines de la Segunda Guerra Mundial enviará diecinueve exposiciones de pintura estadounidense de gira por Latinoamérica, principalmente a aquellos países donde Nelson Rockefeller desarrolló sus inversiones más lucrativas, y en los '60, dirigirá su mirada hacia África y Asia. Cockroft, Eva, "Abstract Expresionism, Weapon of the Cold War", Artforum, June, 1974.

5. Fredric, J. (1997). Periodizar los '60, Argentina, Alción Editora, p. 18.

6. Ibid. p. 27,31 .

7. García Canclini, N. (1999). La Globalización Imaginada. Buenos Aires: Paidós, p. 96. 
8. Curador de la Exposición Artistas latinoamericano del siglo XX, la cual fue fuertemente criticada por las omisiones de artistas y exclusión de los países centroamericanos, la falta de espacio y consecuente apiñamiento de las obras, los criterios monográficos sin conexión ni contexto, entre otros. Goldman, S. M. (1993). Exposición. “Artistas Latinoamericanos del siglo XX, MOMA. Nueva York: Una Repetición del Pasado"ArtNexus, N 56, pp. 84-89.

9. Waldo Rasmussen Entrevista de Goldman, Shifra M. (1993). Exposición. Artistas Latinoamericanos del siglo XX, MOMA. Nueva York: Una Repetición del Pasado ArtNexus, N 56, pp. 84-89.

10. Ibid.

11. Ibid.

12. Žižek, S. (1998). "Multiculturalismo o la lógica cultural del capitalismo multinacional" En: Fredric Jameson y Slavoj Žižek. Estudios Culturales. Reflexiones sobre el Multiculturalismo. Bs. As.: Paidós.

13. Las instancias discursivas desde las cuales los intelectuales del primer mundo han leído las producciones artísticas de las minorías van desde la exotización hasta la sociologización. Para Hal Foster los peligros de la xenofilia, de la pasión por lo exótico, puede derivar hacia una excesiva identificación con el otro y como consecuencia, hacia la alienación de ese otro y el aniquilamiento de su alteridad. Foster, Hal "The Artists as Ethnographer?". En: Fischer, J. (ed.) (1994). Global Vision. Towards a New Internationalism in the Visual Arts, Londres: Kala Press, pp. 12-20.

14. Entre las primeras exposiciones se destacan la muy criticada muestra parisina Magiciens de la Terre (1989) Acusada de fetichización y exotismo, exhibía producciones populares, artistas de áreas marginales y consagrados por las exhibiciones internacionales cuyas obras o ellos mismos fuesen no-occidentales; The Other Store. Afro-Asian Artists in postwar Britain (1989) en la Hayward Gallery de Londres sobre la cual es interesante destacar que incorporaba artistas sudamericanos, principalmente emigrados que aun mantenían ciertos vínculos con la cultura de origen; The Decade Show: Frameworks of Identity in the 1980s, N. Y. (1990), la Documenta 9 de Kassel (1992), Prospect '93 (1993), La Bienal de Venecia (1993) y Cocido y Crudo (1994). 15. Siguiendo los planteos de Homi Bhabha se pensarán las diferencias como "la producción de identidades minoritarias que 'se resquebrajan' (se autoenajenan) en el acto de ser articuladas en un cuerpo colectivo"; en éste sentido, "la articulación social de la diferencia, desde la perspectiva de la minoría, es una compleja negociación en marcha que busca autorizar los híbridos culturales que emergen en momentos de transformación histórica".

Bhabha, H. (2002). El lugar de la cultura, Buenos Aires, Manantial, pp. 18-19.

16. Entre estas cabe destacar InSite y la Bienal de Estandartes de Tijuana.

17. González, V. (2004). "Políticas de la In-diferencia: Representaciones del Mundo en las Exposiciones Internacionales", Ponencia de las III Jornadas de Museología, Centro de Museos de Buenos Aires, 25/26 de octubre.

18. Hernández, C. (2002 "Más allá de la exotización y sociologización del arte latinoamericano". En: Matos, Daniel (Coord.)Estudios y otras Prácticas Intelectuales Latinoamericanas en Cultura y Poder. Caracas: Consejo 
Latinoamericano de Ciencias Sociales (CLACSO), CEAP, FACES, Universidad Central de Venezuela, .

19. Hug, Alfons, "A Bienal como Território Libre”, 26a Bienal de San Pablo, 25 de septiembre /19 de diciembre, 2004.

20. Ibid. p. 24.

21. Ibid. p 23. La explicación del porque San Pablo tuvo una mayor participación es por demás evidente si se considera que es una Bienal Brasilera, desde donde no puede excluir ni las periferias y menos aún a las potencias que rigen al mercado artístico. Por otra parte, surge 56 años más tarde, poco tiempo antes de que el Tercer Mundo adquiriese una gran repercusión en las metrópolis europeas y norteamericanas. Ibid. p 23.

22. Ibid. p. 24.

23. Ibid. p.24.

24. Ibid. p. 23

25. González, V. (Op. cit.).

26. Hug, A. (2004). “A Bienal como Território Libre”, 26ª Bienal de San Pablo, 25 de septiembre - 19 de diciembre, p. 28

27. Ver De Andrade, Oswald, "Manifiesto Pau Brasil", "Manifiesto Antropofágico", en: Schwartz, J. (1991). Las Vanguardias Latinoamericanas, textos programáticos y críticos. Cátedra, pp. 137-141 y 143-153.

28. Idios= propio, particular; rhythmós=ritmo, fugitividad del código, intersticio. Barthes, R. (2003). Cómo Vivir Juntos: Simulaciones Novelescas de Algunos Espacios Cotidianos, Buenos Aires, Siglo XXI, p. 51.

29. Barthes, R. (Op. cit.), p. 49.

30. Hernández, C. (Op. cit.) 31. Barriendos, J. (2009). "Desconquistas (Políticas) y Redescubrimientos (Estéticos). Geopolítica del Arte Periférico en la Víspera de los Bicentenarios de América Latina”. Revista Desbordes. Resonancias desde los Límites del Arte y la Política, № 0, enero 2009. Disponible en: http://www.desbordes.net/des-bordes/joaquin_barriendos.php Abstract:

In recent times the interest of the great centers on the peripheries comes from decolonization, globalization and demographic processes. In the new world order, the art scene has been altered, leading to rethink it as a field of interest and negotiations. The world postmodern pluralist perspective has prompted the inclusion of the periphery within international art exhibitions. When considering the curators of the exhibition of international art as social control agents of the art sense, you may rethink its role as an essential aspect of the inclusion of the periphery within that artistic field. From this perspective, this article reflects on, to what extent curatorial practices, they are also political and social strategies; discursive constructions that shape not only an artistic conception of space but, through it, impulse a particular view of the world. 
Key words:

latin american art - curatorial practices - local - Global - Pluralism - posmodernism - artistic field occidentalization - international.

\section{Resumo:}

Nos últimos tempos, o interesse dos grandes centros sobre as periferias provém dos processos de descolonização, globalização e demográficos. Na nova ordem mundial, o circuito artístico sofreu modificações, que conduzem a re-pensar o circuito como um campo de interesses e negociações. A perspectiva pluralista do mundo pós-moderno impulsionou a inclusão das periferias dentro das exibições internacionais de arte.

Considerando aos curadores das exposições de arte internacional como agentes sociais de controle do sentido da arte, é possível re-pensar seu rol como um aspecto essencial na inclusão das periferias dentro daquele campo artístico. Desde esta perspectiva, vai se refletir até onde as práticas curatoriais não são também estratégias políticas e sociais, construções discursivas que modelam não somente uma concepção do espaço artístico senão que, através dela, promovem uma leitura do mundo.

Palavras chave:

arte latino-americana - práticas curatoriais - local - global - pluralismo - pós-moderno - campo artístico ocidentalização - internacionalismo.

El arte local en el contexto global fue publicado de la página 21 a página29 en Cuadernos del Centro de Estudios de Diseño y Comunicación $N^{\circ} 60$ 